\title{
Pengendali Robot Tempat Sampah Menggunakan Smartphone Berbasis Boarduino
}

\author{
Andri Fadjria*1, Rakhmat Purnomo ${ }^{2}$, Nur Rahman ${ }^{3}$ \\ 1,2,3 Teknik Informatika, Fakultas Teknik Ubhara Jaya, Jakarta \\ e-mail: ${ }^{1 *}$ andri.fajria@dsn.ubharajaya.ac.id, ${ }^{2}$ rakhmat.purnomo@dsn.ubharajaya.ac.id, \\ ${ }^{3}$ nurrahman941.nr@gmail.com
}

\begin{abstract}
Abstrak
Kantin Universitas Bhayangkara Jakarta Raya, memiliki permasalahan yaitu banyak sampah yang di tinggalkan oleh para pengunjung kantin. Sampah terdiri dari plastik, kertas, sisa makanan yang diletakkan pada meja kantin oleh pengunjung kantin. Letak tempat sampah yang jauh dari pengunjung, dan jumlah tempat sampah yang berjumlah 4 buah, belum bisa menampung sampah-sampah dari pengunjung kantin maka bisa mendapatkan permasal ahan dalam pencemaran lingkungan untuk kedepannya. Maka dibuatnya penelitian yang menghasilkan robot tempat sampah dengan sistem industri 4.0, yaitu untuk membantu tugas dari pekerjaan manusia. Dengan tujuan untuk mengurangi sampah-sampah yang ditinggalkan para pengunjung kantin dan kemudahan para pengunjung untuk meletakkan sampah pada robot tersebut. Menggunakan metode protoyping dalam sistem pembuatan robot tempat sampah dengan tahapan pengumpulan kebutuhan proses desain, membangun prototype ,evaluasi \& perbaikan, menghasilkan sebuah robot dengan pengendali smartphone berbasis aplikasi boarduino sehingga robot bisa bekerja sesuai kebutuhan yang diharapkan oleh peneliti
\end{abstract}

Kata kunci : Robot, Sampah, Smartphone, Prototyping, Boarduino

\begin{abstract}
The cafeteria of Bhayangkara University, Greater Jakarta, has a problem that is a lot of garbage left by visitors to the canteen. Waste consists of plastic, paper, food scraps placed at the canteen table by visitors to the canteen. The location of the trash can is far from the visitors, and the number of trash bins totaling 4 pieces, unable to accommodate the garbage from visitors to the canteen can get problems in environmental pollution for the future. So he made a study that produced a garbage bin robot with an industrial system 4.0, which is to assist the task of human work. With the aim of reducing the trash left by visitors to the canteen and the convenience of visitors to put garbage on the robot. Using the protoyping method in the system of making garbage bins with the stages of collecting design process needs, building prototypes, evaluating \& repairing, producing a robot with a smartphone controller based on boarduino applications so that robots can work according to the needs expected by researchers.
\end{abstract}

Keywords : Robot, Garbage, Smartphone, Prototyping, Boarduino 


\section{PENDAHULUAN}

Dewasa ini berbagai jenis robot telah dikembangkan untuk membantu pekerjaan dari tugas manusia sehari-hari, salah satunya adalah robot berkaki dan robot beroda yang secara otomatis sistem kontrolnya menggunakan sensor maupun yang dikendalikan manusia secara manual melalui remote controle[1]. Salah satu fungsi robot adalah untuk membersihkan ruangan melalui aktivitas mengepel lantai kotor[2]. Oleh karenanya telah banyak diciptakan robot pengepel lantai otomatis pada bawah depan robot. Kantin Ubhara Jaya, memiliki permasalahan yaitu banyak sampah yang di tinggalkan oleh para pengunjung kantin. Sampah terdiri dari plastik, kertas, sisa makanan yang diletakkan pada meja kantin oleh pengunjung kantin. Permasalahan tersebut karena letak tempat sampah dari lokasi pengunjung kantin yang jauh, dan permasalahan pada tempat sampah berjumlah 4 tempat sampah masih kurang mampu menampung jumlah volume dari sampah pengunjug kantin. Sampah keseluruhan yang ada dikantin dalam satu hari bisa mencapai berat lebih dari $50 \mathrm{Kg}$, dan sampah sisa makanan dan kemasan yang di tinggalkan dimeja maupun tidak dibuang pada tempatnya oleh pengunjung kantin bisa mencapai $10 \mathrm{Kg}$ perhari.

Saat ini industri teknologi sudah berada pada industri 4.0, yaitu menggabungkan sistem informasi, basis data dan kecerdasan buatan untuk membantu pekerjaan manusia dalam kehidupannya sehari-hari. Semua ini membantu industri untuk mengintegrasikan real world menjadi virtual dan memungkinkan mesin mengumpulkan data secara langsung, menganalisisnya bahkan membuat keputusan berdasarkan data yang sudah di proses. Sebagai contoh adalah smartphone Dengan demikian tujuan utama dari 4.0 yaitu kestabilan distribusi barang serta kebutuhan manusia untuk membantu permasalahan, dapat terpenuhi

\section{Robot}

Menurut definisi dari kamus Meriam-Webster, robot merupakan mesin yang memiliki fungsi seperti manusia, melakukan banyak aktivitas yang kompleks dari manusia antara lain berjalan, berbicara, atau suatu alat yang bekerja secara otomatis. Robot umumnya diprogram agar dapat melakukan pekerjaan berulang - ulang dan memiliki prosedur yang diatur oleh kontrol otomatis[3]. Sedangkan robotika marupakan cabang teknologi yang berkaitan dengan desain, konstruksi, operasi, dan aplikasi dari robot. Robotika adalah cabang ilmu yang mempelajari semua hal tentangrobot. Cabang ilmu tersebut meliputi perancangan mesin robot, unsur elektronika, sistem pengontrolan, pemprograman, dan kecerdasan buatan.

Terdapat pendapat lain mengenai pengertian robot, seperti sampaikan oleh Robotic Institute of America, pada tahun 1979 mendefinisikan dalam bentuk formal tentang robot adalah manipulator multi fungsi yang dapat diprogram ulang sehingga dapat dirancang untuk menggerakkan material, alat, atau perangkat khusus melalui sejumlah gerakan terprogram sehingga dapat melakukan aktifitas spesifik.

\section{Mikrokontroler Arduino}

Arduino merupakan papan rangkain elektronik yang didalamnya terdapat komponen utama, yaitu sebuah chip mikrokontroler dengan jenis AVR[4]. Mikrokontroler ini dapat diprogram menggunakan komputer. Tujuannya adalah agar rangkaian elektronik dapat membaca input, memprosesnya dan kemudian menghasilkan output sesuai yang diinginkan. Jadi mikrokontroler bertugas sebagai otak yang mengendalikan input, proses dan output. 


\section{Aplikasi Boarduino}

Aplikasi boarduino adalah salah satu aplikai open source yang digunakan dalam membantu penggunaan remote control pada robot. Yang teintegrasi dengan module bluetooth. Aplikasi ini memiliki tiga total control yaitu Recontooth ditujukan untuk mengktifkan empat buah relay modul, Voicetooth untuk mengontrol Arduino via Voice command (perintah suara), dan terakhir Textduino aplikasi mengontrol Arduino via text (tulisan). Dengan adanya total control yang ada pada aplikasi ini seorang user bisa menggunakan perintah via suara yang memberikan kemudahan dalam pemggunaannya dan menjadi suatu kelebihan dalam aplikasi ini untuk menggunakannya.

\section{METODE PENELITIAN}

Penulis membuat kerangka penelitian dengan tahap penelitian yang akan dilakukan ialah mengidentifikasi adanya permasalan yang ada di kantin universitas bhayangkara. Dengan menentukan tujuan penelitian dan melakukan kuisoner dan wawancara terhadap petugas kebersihan kantin, terkait dengan permasalahan yang sedang penulis teliti. Mendesain penelitian yang akan digunakan mulai dari pengumpulan data hingga menganalisisnya, merancang dan membuat robot tempat sampah yang akan digunakan petugas kantin.

Melakukan ujicoba terhadap robot yang dibuat, metode yang digunakan dalam robot ini adalah metode prototype.

Dan bisa terlihat pada di gambar bawah ini.

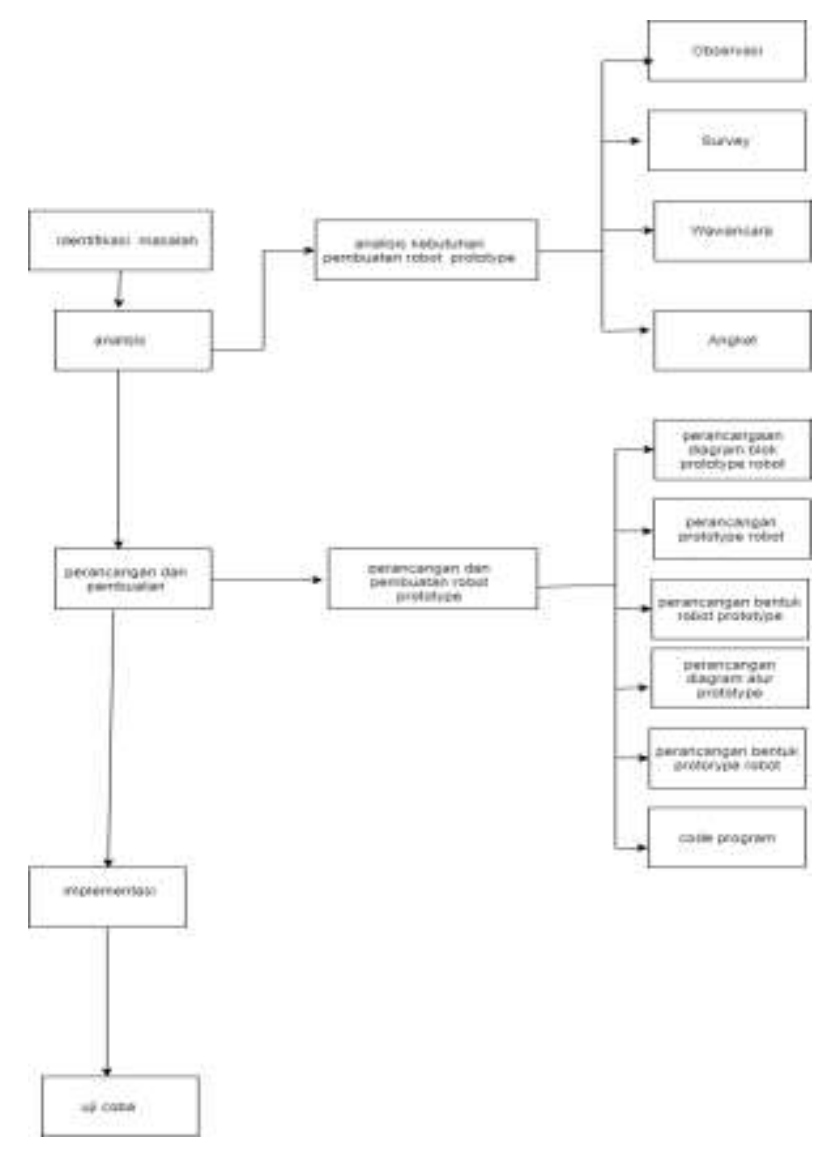

Gambar 1. Kerangka Pemikiran 


\section{Analisis Sistem Berjalan}

Analisis sistem berjalan adalah suatu kegiatan dari penguraian suatu sistem yang menyeluruh kedalam setiap bagian komponennya dengan tujuan untuk mengidentifikasi dan evaluasi permasalahan-permasalah yang terjadi didalam sistem maupun objek yang sedang diteliti dan semua kebutuhan yang diharapkan sehingga dapat diusulkan menjadi perbaikan sistem yang lebih baik. Adapun sistem berjalan pada kantin Universias Bhayangkara Jakarta Raya berdasarkan berikut :

Flowmap sistem berjalan pada petugas kebersihan kantin universitas Bahayangkara Jakarta Raya :

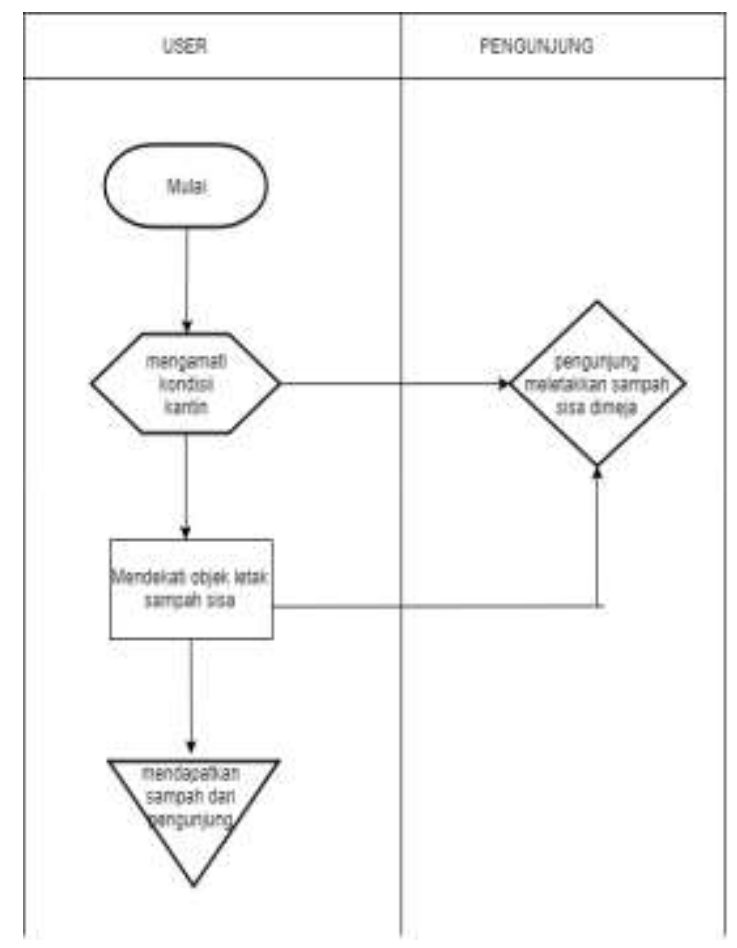

Gambar 2. Sistem Berjalan

\section{Permasalahan}

Berdasarkan masalah dan analisis kebutuhan sistem diatas, proses kebersihan khususnya dalam mengambil sampah sisa pada kantin universitas masih menggunakan peralatan yang manual dan memiliki permasalahan.

Adapun permasalahannya adalah sebagai berikut :

1. Banyaknya penumpukan sampah sisa pada meja dikantin Ubhara Jaya pada jamjam sibuk.

2. Masih minimnya peralatan maupun tempat sampah sebagai sarana dan prasarana kebersihan kantin.

3. Kesadaran dalam membuang sampah ditempatnya oleh para mahasiswa maupun pengunjung masih minim 


\section{Analisis Usulan Sistem}

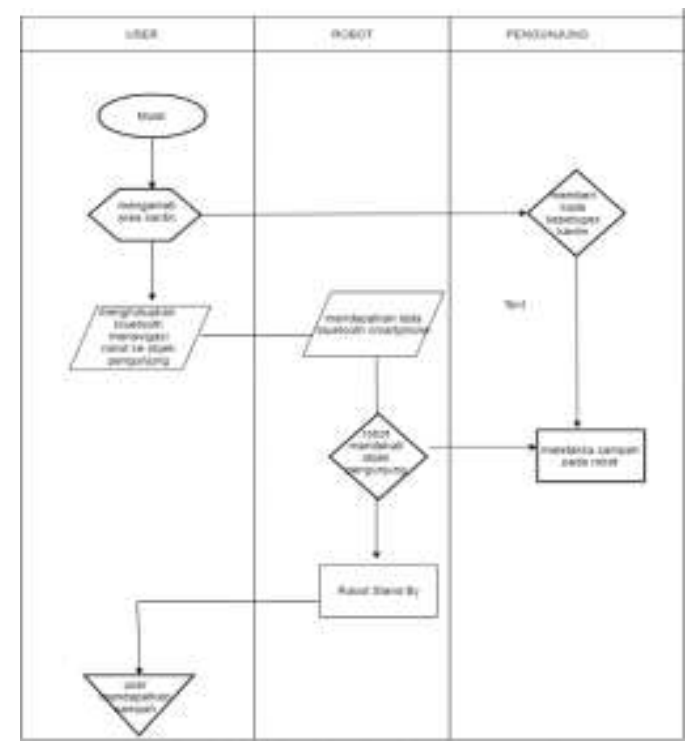

Gambar 3. Analisis Sistem Usulan

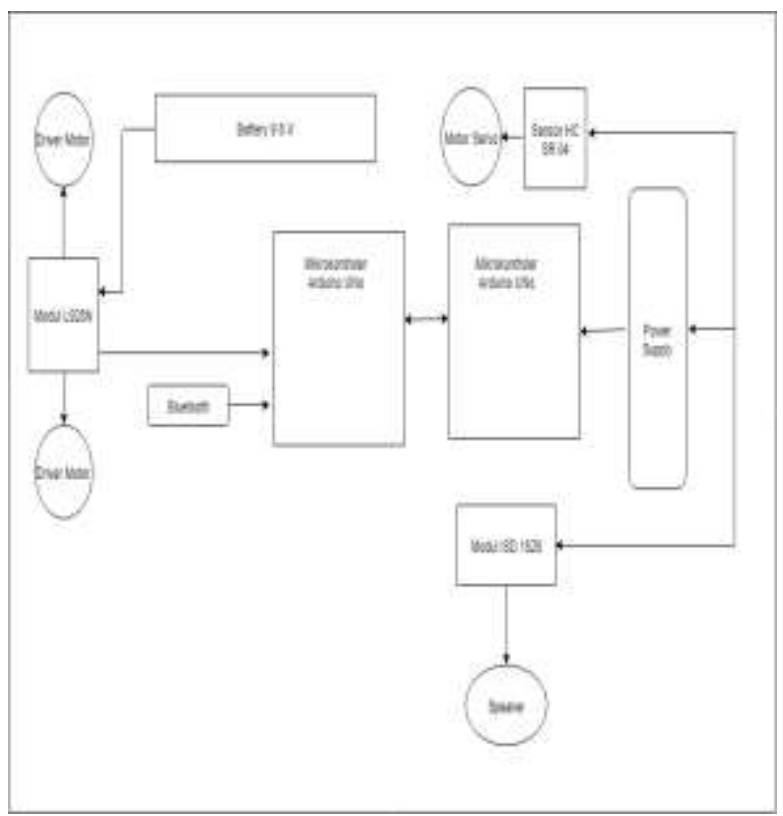

Gambar 4. Diagram Blok Robot 
a) Analisis Sistem Susulan

Sistem yang diusulkan adalah sebuah robot yang berbasis mikrokontroler Arduino Uno dan menggunakan sensor HC-04 sebagai sensor jarak penutup tempat sampah, speaker modul ISD 1820, sebagai media informasi suara, dan aplikasi boarduino sebagai pengendali remote control robot tersebut.

\section{b) Metode Kinerja Aplikasi Usulan}

Robot yang berbasis mikrokontroler Arduino Uno ini memberi kemudahan membuang sampah dikantin, dikarenakan sebagai tempat sampah yang memiliki edukasi dan inovasi yang berbeda dari sebelumnya, dengan adanya sensor HC-04 sebagai sesnsor jarak, otomatis tempat sampah akan terbuka secara langsung tanpa harus memegangnya dan modul isd 1820 memiliki nilai informsi untuk para pengunjung untuk membuang sampah pada robot tersbut, dan aplikasi boarduino bertugas sebagai remote control dalam menjalankan robot tersebut, dan mempunyai kelebihan yaitu bisa mengirim perintah lewat voice pada untuk menjalankan robot tersebut.

\section{HASIL DAN PEMBAHASAN}

\section{Perancangan}

Peneliti merancang sebuah informasi agar para pengunjung kantin membuang sampah pada robot tempat samah, dan robot tempat sampah dengan mikrokontroler Arduino Uno sebagai chip utama pada robot tempat sampah. Inputan dari robot yang dibangun berasal dari inputan pengendali dengan menggunakan smartphone yang terintegrasi dengan bluetooth robot, modul isd 1820 menghasilkan suara, sensor hc-sr 04 sebagai sensor jarak pendeteksi tangan pengunjung kantin.

Sistem kontrol megggunakan sumber daya batterai dengan tegangan 9,6 volt yang merupakan sumber daya tambahan dikarenakan sumber daya utama yaitu powerbank untuk arduino sangat minim untuk keseluruhan untuk robot, dan kemudian kerangkaian power supply dan selanjutnya akan disebarkan ke keseluruhan sistem rangkaian robot tempat sampah, tertera pada gambar dibawah ini.

\section{Hasil Perancangan Perangkat Keras}

Setelah serangkain telah dibuat dari model software dan desain robot maka tahapan selanjutnya adalah implementasid dari robot, berikut ditampilkan hasil rancangan perangkat keras berupa robot tampat sampah 


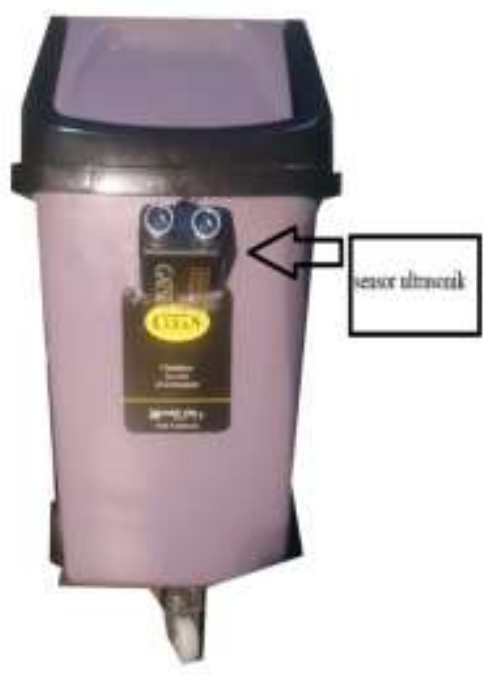

Gambar 5. Robot tampak depan

Keterangan : Dari gambar diatas terdapat sesnor HC-SR 04, yang berguna sebagai sensor jarak, agar robot bisa membuka otomatis tutup pada tempat sampah yang memudahkan pengguna untuk membuang sampah.

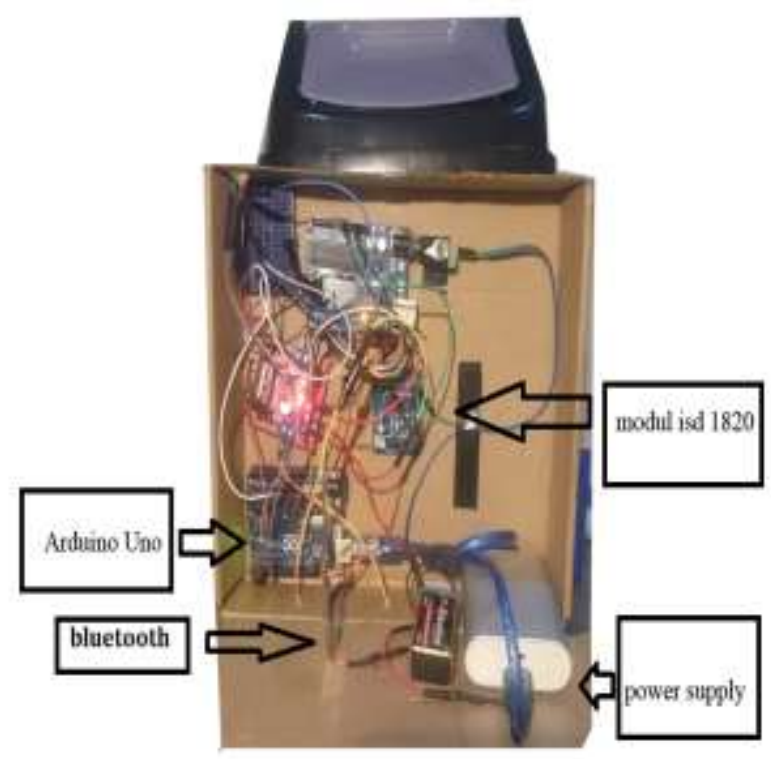

Gambar 6. Robot Tampak Belakang

Dari gambar tersebut menggunakan power supply yaitu powbank, dan battery berdaya 9 Volt sebagai penghubung khusus ke modul L928N untuk terhubung ke motor DC, dan arduino uno sebagai motor penggerak utama pada sistem tersebut. Dan bluetooth sebagai sistem untuk terhubung dengan smartphone user, agar robot tersebut bisa di navigasi. 


\section{Pengujian Sistem}

Pengujian sistem merupakan proses akhir dari serangkaian perancangan hardware dan software, apakah sistem tersebut bisa berjalan dengan baik ataupun ada beberapa kemungkinan trouble system.

Pengujian sistem digunakan menggunakan Black Box. Pengujian Black Box yaitu menguju perangkar dari segi spesifikasi fungsional tanpa menguji dari bentuk desain dan maupun source code program yang telah dibuat. Pengujian bertujuan untuk mengetahui apakah setiap fungsi dan keseluruhan bisa dilakukan dengan baik dan secara optimal. Dalam melakukan pengujian, tahapan-tahapan yang dilakukan pertama kali adalah melakukan pengujian ,terhadap perangkat inputan seperti sensor,bluetooth, dan modul suara. Kemudian melakukan pengujian secara keseluruhan sistem kontrol robot.

Adapun tahapan-tahapan dalam pengujian sistem kotrol robot ini adalahs sebagai berikut.

Tabel 1. Black Box Pengujian

\begin{tabular}{|l|l|l|l|l|}
\hline No & \multicolumn{1}{|c|}{$\begin{array}{c}\text { Deskripsi } \\
\text { Pengujian }\end{array}$} & \multicolumn{1}{|c|}{ Tahap Pengujian } & $\begin{array}{l}\text { Hasil yang } \\
\text { Diharapkan }\end{array}$ & Hasil Pengujian \\
\hline 1. & Arduino Uno & $\begin{array}{l}\text { Menerima input, } \\
\text { melakukan proses, } \\
\text { mendapatkan output. }\end{array}$ & $\begin{array}{l}\text { Input dan } \\
\text { output yang } \\
\text { dihasilkan } \\
\text { optimal }\end{array}$ & $\begin{array}{l}\text { Modul Isd 1820 } \\
\text { Modul Bluetooth }\end{array}$ \\
\hline 2. & Modul Bluetooth & $\begin{array}{l}\text { Menerima tegangan } \\
\text { dari Arduino uno dan } \\
\text { mengaktifkan sinyal } \\
\text { bluetooth dari } \\
\text { smartphone untuk } \\
\text { ardunio uno }\end{array}$ & $\begin{array}{l}\text { Mencari } \\
\text { bluetooth, } \\
\text { menjalankan } \\
\text { sinyal robot } \\
\text { hingga 10 } \\
\text { meter }\end{array}$ & $\begin{array}{l}\text { Robot } \\
\text { Bisa } \\
\text { Berjalan } \\
\text { Sesuai } \\
\text { Arah yang } \\
\text { Diinginkan } \\
\text { User }\end{array}$ \\
\hline 3. & $\begin{array}{l}\text { Sensor HC-SR 04 } \\
\text { (Jarak) }\end{array}$ & $\begin{array}{l}\text { Menerima data jarak } \\
\text { pengguna agar bisa } \\
\text { bekerja untuk motor } \\
\text { servo dalam tugasnya }\end{array}$ & $\begin{array}{l}\text { Membuka dan } \\
\text { menutup ketika } \\
\text { pengguna } \\
\text { mendekatkan } \\
\text { tangan ke robot } \\
\text { tempat sampah }\end{array}$ & $\begin{array}{l}\text { Robot membuka } \\
\text { Tempat sampah } \\
\text { Otomatis ketika } \\
\text { Ada objek yang } \\
\text { mendekati pada } \\
\text { sensor hc-sr 04. }\end{array}$ \\
\hline 4. & $\begin{array}{l}\text { Modul ISD 1820 } \\
\text { (Suara) }\end{array}$ & $\begin{array}{l}\text { Mendapatkan data } \\
\text { dari jarak sensor HC- } \\
\text { SR 04 untuk } \\
\text { melakukan kegiatan } \\
\text { voice (Suara) }\end{array}$ & $\begin{array}{l}\text { Memberikan } \\
\text { voice suara } \\
\text { "terima kasih" } \\
\text { ketika tutup } \\
\text { tempat sampah } \\
\text { terbuka }\end{array}$ & $\begin{array}{l}\text { Robot } \\
\text { mengeluarkan } \\
\text { Voice ketika } \\
\text { Ada objek yang } \\
\text { Meletakkkan } \\
\text { sampah pada } \\
\text { robot tersebut. }\end{array}$ \\
\hline
\end{tabular}

\section{KESIMPULAN}

Dalam penelitian penyusunan skripsi perancangan Robot Tempat Sampah Dengan Pengendali Smartphone Berbasis Aplikasi Boarduino dikantin Ubhara Jaya dapat mengambil kesimpulan yaitu :

1. Robot tempat sampah dapat membantu meningkatnya pengunjung kantin untuk meletakkan sampah pada robot tersebut, untuk tidak meninggalkan sampah di kantin. 
2. Dengan adanya robot tempat sampah ini, mempermudah pengunjung untuk meletakkan sampah pada robot, tidak perlu mencari letak tempat sampah yang ada di kantin Ubhara Jaya.

3. Robot tempat sampah, dapat membantu keterbatasan tempat sampah, karena robot tempat sampah bisa menampung sampah dari pengunjung kantin.

\section{SARAN} berikut :

Untuk penelitian yang akan datang terdapat beberapa saran dilakukan sebagai

1. Untuk hasil yang maksimum, menyarankan untuk menggunakan modul wi-fi agar jarak kendali robot, bisa lebih jauh. Karena menggunakan bluetooth HC-05 masih cenderung jauh untuk daya jangkaunya.

2. Untuk tahapan selanjutnya robot dilengkapi dengan lengan, agar sampah-sampah yang ada di lantai kantin bisa di capai dan lebih efisien dalam penggunaannya.

3. Robot menggunakan sistem $4 \mathrm{WD}$ agar robot tersebut lebih balance dalam operasional tugasnya.

4. Menggunakan sistem IOT sehingga tidak dibutuhkan user untuk mengendalikannya.

\section{DAFTAR PUSTAKA}

[1] R. Hidayat, "Bak Sampah Otomatis Berbasis Robot Line Follower Sebagai Sarana Kemudahan dalam Membuang Sampah di Rumah Sakit," Barometer, vol. 2, no. 2, pp. 70-77, 2017.

[2] D. Setiawan, T. Syahputra, and M. Iqbal, "Rancang Bangun Alat Pembuka dan Penutup Tong Sampah Otomatis Berbasis Mikrokontroler," Teknol. dan Sist. Informasi2, vol. 1, no. 1, pp. 55-62, 2014.

[3] H. J. Wahyudi, A. Rusdinar, and Y. S. Hariyani, "Perancangan dan Realisasi Robot Line Follower untuk Pengangkut Sampah Otomatis," in e-Proceeding of Applied Science, 2015, vol. 1, no. 3, pp. 2693-2700.

[4] A. Fakhrana, "Pembuatan Prototype Robot Kapal Pemungut Sampah Menggunakan Mikrokontroler Arduino Uno dengan Aplikasi Pengendali Berbasis Android," Teknol. Reyakaya, vol. 21, no. 3, pp. 185-195, 2016. 